\title{
Expresión de Receptores de Estrógenos y Progesterona en el Tracto Genital de Ovejas Raza Texel
}

\author{
Expression of Estrogen and Progesterone Receptors in the Genital Tract of Texel Ewes \\ *,**Adriana Vasconcellos C.; ${ }^{* *}$ Marco Paredes H.; ${ }^{* *}$ Carla Hernández V.; ${ }^{* *}$ Aniela Muñoz S. \& ${ }^{* *}$ Javiera Navarrete
}

VASCONCELLOS, C. M.; PAREDES, H. M.; HERNÁNDEZ, V. C.; MUÑOZ, S. A. \& NAVARRETE, J. Expresión de receptores de estrógenos y progesterona en el tracto genital de ovejas raza Texel. Int. J. Morphol., 29(4):1268-1273, 2011.

RESUMEN: El comportamiento reproductivo de los ovinos varía entre las diferentes razas. Dentro de los factores que inciden en la capacidad reproductiva, el nivel de expresión de receptores de estrógenos y progesterona en su tracto genital parece tener un rol relevante. En el endometrio, oviducto y ovario los estrógenos y progesterona, regulan la expresión de numerosas proteínas comprometidas en su desarrollo morfofuncional. Factores genéticos como la raza estarian relacionados con los niveles de expresión de estos receptores. Las ovejas de raza Texel tienen elevados índices de fertilidad, son muy prolíficas y presentan un alto porcentaje de gestación múltiple lo cual podría tener relación con la expresión de estos receptores en el tracto reproductivo. El objetivo del presente estudio fue evaluar la expresión de receptores de estrógenos y progesterona en tracto genital de ovejas de raza Texel de alta prolificidad. La expresión de la proteína receptora de ambos receptores se detectó mediante análisis inmunohistoquímico y el nivel de expresión de los transcritos por RT-PCR en Tiempo Real Cuantitativo. Los resultados muestran expresión inmunohistoquímica del receptor de estrógeno principalmente en zonas glandulares y carunculares del endometrio. Se destaca además una menor expresión de ambos receptores en ovario, epitelio del oviducto y cervix. La expresión del receptor de progesterona a nivel inmunohistoquímico es bastante menor en cuanto a la señal destacándose marcas débiles en endometrio y ovarios. El nivel de expresión de los transcritos mantiene la misma distribución que las señales inmunohistoquimicas para ambos receptores. Concluimos que ambos receptores son expresados en el sistema reproductivo de ovejas de raza Texel en una distribución similar a lo encontrado en otras razas de ovejas quedando por definir si los niveles de expresión son similares en las distintas razas.

PALABRAS CLAVE: Sistema reproductor; Receptor de estrógeno; Receptor de progesterona; Ovejas raza Texel.

\section{INTRODUCCION}

Las diferencias fisiológicas entre distintas especies y sus razas, hacen de la reproducción un fenómeno complejo. Su estudio requiere el conocimiento de las características individuales de cada especie (Cunningham, 1998; Priedkkalns, 1993). Los estrógenos y la progesterona son las hormonas responsables de la diferenciación sexual, desarrollo, crecimiento y comportamiento reproductivo en mamíferos (Meikle et al., 2004). Estas actúan uniéndose a sus receptores específicos, desencadenando como consecuencia expresión de genes y alteraciones celulares metabólicas y proliferativas (Meikle et al., 2004). De este modo, el efecto de estas hormonas está relacionado con el nivel de expresión y distribución de sus receptores en los tejidos blancos. Es conocida en ovinos, la acción de las hormonas sexuales a nivel del aparato reproductor de la hembra, animal poliéstrico estacional, en el cual se han descrito los cambios que inducen en el útero durante el periodo fetal, neonatal (Wiley et al., 1987) y durante sus fases reproductivas (Cherny, 1991; Ing \& Ott, 1999; Meikle et al., 1997; Meikle et al., 2001; Meikle et al., 2004; Spencer \& Bazer, 1995; Vasconcellos et al., 2009a).

A diferencia de otros mamíferos en el endometrio de las ovejas se encuentran receptores de estrógenos y progesterona fisiológicamente activos desde la etapa prepuberal (Meikle et al., 2004; Vasconcellos et al., 2006), no conociéndose aún el significado fisiológico de esta expresión temprana de receptores en borregas. La presencia de estos receptores durante el periodo reproductivo es fundamental ya que comenzada la actividad ovárica intervienen en los cambios que se producen en el endometrio durante el ciclo estral

\footnotetext{
" CEBIOR, Centro Biotecnológico de la Reproducción, Universidad de La Frontera, Temuco, Chile.

${ }^{* *}$ LINBA, Laboratorio de Investigación en Biotecnología Animal, Departamento de Ciencias Básicas, Universidad de La Frontera, Temuco, Chile. Proyecto DIUFRO DI09-103, Universidad de La Frontera, Chile.
} 
(Cherny; Meikle et al., 2001; Vasconcellos et al., 2009b). Factores genéticos como raza y factores exógenos como la nutrición parecen estar relacionados con los niveles de expresión de la proteína receptora y su RNA mensajero.

Hay pocos estudios en los que, la mayor parte de ellos en forma tangencial, se hayan analizado posibles variaciones en la expresión molecular de los receptores de estrógeno y progesterona en razas distintas lo que podría condicionar cambios morfofuncionales diferentes. Las ovejas de raza Texel tienen elevados índices de fertilidad y presentan un porcentaje alto de gestación múltiple lo cual podría estar relacionado con una mayor expresión de receptores en el endometrio

El objetivo del presente estudio fue evaluar la expresión de la proteína receptora como del transcrito de ambos receptores mediante análisis inmunohistoquímico y RT-PCR en tiempo real respectivamente. en ovejas Texel, raza de alta prolificidad.

\section{MATERIAL Y MÉTODO}

Animales y preparación de muestras biológicas. Se utilizaron 4 ovejas de raza Texel en periodo de ciclo inicial, mantenidas en el Campo Experimental Maquehue de La Universidad de La Frontera (Región de la Araucanía) hasta su sacrifico y de acuerdo con el consentimiento del Comité de Ética de la Facultad de Medicina de La Universidad de La Frontera, Chile.

Para el estudio se utilizaron muestras de tejidos correspondientes a ovario, oviducto, cuerno y cérvix. Una serie de muestras se fijaron en Bouin acuoso para técnicas convencionales e inmunohistoquímica (IHQ) y otra se congelaron a -80 C para extracción de RNA total.

Análisis inmunohistoquímico. Las muestras fijadas se incluyeron en Paraplast (Merck, Alemania) y posteriormente se prepararon cortes de 5 micras a partir del tejido incluido. Los cortes se procesaron eliminado el Paraplast con xilol y luego se hidrataron mediante incubación en una batería de concentración decreciente de etanol. Posteriormente, se eliminó la actividad de peroxidasas endógenas incubando con $\mathrm{H} 2 \mathrm{O} 2$ al $3 \%$ en metanol por $10 \mathrm{~min}$. Se lavó luego, dos veces con tampón fosfato salino (PBS) por 5 minutos cada vez y se procedió a incubar los cortes en solución de bloqueo (BSA $1 \%$ y tritón X 100 0,3\%, diluidos en PBS) a temperatura ambiente por 30 minutos. Los cortes se incubaron a continuación con un anticuerpo policlonal anti-RE (H-184; Santa Cruz Biotechnology, USA) y anticuerpo monoclonal anti-RP (NeoMarkers, USA) el primero diluido 1:500 y el segundo
1:1000 en solución de bloqueo durante 12 horas a temperatura ambiente. Posteriormente los cortes se lavaron 3 veces por 5 minutos cada vez con PBS. En adelante se utilizó el sistema de detección LSABTM Kits (Dako, USA) el cual se basa en el reconocimiento del primer anticuerpo por un segundo anticuerpo anti-IgG conjugado a biotina el cual interacciona específicamente con el complejo estreptoavidina conjugada a peroxidasa. Los lavados y tiempos de incubación se efectuaron de acuerdo a las instrucciones del fabricante del kit. El revelado se realizó incubando en diaminobencidina $(0,5 \%)$ y perhidrol (1\%) en PBS, a temperatura ambiente por 5 a 10 min. La muestra histológica se lavó con agua destilada y seguidamente se tiño para contraste nuclear, con hematoxilina. Seguidamente, se deshidrató en una batería creciente de etanol y se diafanizó con xilol. Finalmente los cortes se montaron con resina Entellan (Merck). El análisis microscópico y captura de imágenes digitales se efectuó utilizando un microscopio Laborlux 12 (Leitz).

Análisis de expresión de los transcritos de RP y RE. El nivel de expresión de lostranscritos de RE y RP en el endometrio de oveja, se evaluó por medio de RT-PCR en tiempo real mediante el método "Comparative $\Delta \Delta \mathrm{Ct}$ " (Pfaffl, 2001) utilizando el sistema de amplificación en tiempo real "Step One" de Applied Biosystem (USA). Para esto, se extrajo inicialmente RNA a partir de cuerno uterino según metodología descrita por Chomczynski \& Sacchi (1987). Para estimar la concentración del RNA obtenido se utilizó la ecuación [RNA] = OD260 × FD x $40 \mathrm{mg} / \mathrm{mL}$, donde FD es el factor de dilución utilizado y OD260 la absorbancia medida a $260 \mathrm{~nm}$. Mientras que la pureza se evaluó mediante la razón de absorbancia OD260/OD280, considerado valores de de 1,8 a 2 como buena estimación de pureza. El RNA obtenido se utilizó para preparar ADN complementario (cDNA) mediante el uso del kit "High Capacity RNA to cDNA kit" (Applied Biosystems, USA). Para ello, se utilizaron $2 \mathrm{mg}$ de RNA total, el cual se mezcló con $5 \mathrm{~mL}$ de tampón RT $2 \mathrm{X}$ y $0,5 \mathrm{~mL}$ del de enzimas 20X (transcriptasa reversa y RNasa $\mathrm{H}$ ) provistas por el fabricante del kit. La mezcla de reacción se completó a $10 \mathrm{ml}$ de volumen final con agua ultrapura y se incubó a $37^{\circ} \mathrm{C}$ por 60 minutos, finalmente reacción de trascripción se detuvo incubando a $90^{\circ} \mathrm{C}$ por 5 minutos. El cDNA obtenido se utilizó como templado para amplificación específica de RE, RP y b -actina cuya expresión constitutiva se utilizó como control endógeno referencial para la cuantificación relativa. Los cDNAs de RE y RP se amplificaron por PCR en tiempo real, mezclando $1 \mathrm{~mL}$ del respectivo cDNA con $10 \mathrm{~mL}$ del tampón de reacción Power SYBR Green PCR Master Mix 2X (Applied Biosystem), $7 \mathrm{~mL}$ de agua ultrapura y $1 \mathrm{~mL}(10 \mathrm{mM})$ de cada uno del par de partidores RE-S/RE-A (Tabla 1) o RPS/RP-A (Tabla I) ambos pares concentrados a $10 \mathrm{mM}$. El cDNA de b-actina se amplificó con mezclas de reacciones similares a las descritas para RE y RP, pero utilizando el par 
de partidores específicos OB-A/OB-S a 10mM cada uno (Tabla I). Todas las reacciones se realizaron en un volumen de reacción final de $20 \mathrm{~mL}$. Las condiciones térmicas de amplificación para los tres genes fueron similares y se programaron con un ciclo inicial de 10 minutos a $95^{\circ} \mathrm{C}$, seguido por 45 ciclos compuestos cada uno por una denaturación a $95^{\circ} \mathrm{C}$ por 20 segundos, hibridación a $60^{\circ} \mathrm{C}$ por 20 segundos y extensión a $72^{\circ} \mathrm{C}$ por 20 segundos. Se programó al término de los 45 ciclos de amplificación, un ciclo para el análisis de las temperaturas de fusión (melting) de los amplicones, lo cual permitió evaluar la especificidad de la reacción de amplificación y descartar de este modo el efecto de productos no específicos sobre la cuantificación.

Obtención de partidores para amplificación de RE y RP. Los partidores utilizados para el análisis por PCR en tiempo real (Tabla I) se derivaron a partir de la secuencias del cDNA de los receptores de estrógeno y progesterona de oveja disponible en la base de datos GenBank (http:// www.ncbi.nlm.nih.gov). El diseño bioinformático de los partidores se efectuó con el programa "Primer 3" (http:// primer3.sourceforge.net/). Los partidores utilizados para amplificar el cDNA de b -actina (Tabla I) son los descritos por Dzidic et al. (2004).

\section{RESULTADOS}

La expresión inmunohistoquímica indica que en endometrio existe una marcada señal inmunoreactiva para ambos receptores (Figs. 1 y 2), destacándose en este tejido

Tabla I. Partidores para análisis de expresión de los receptores de estrógeno (RE-S/ RE-A) y progesterona (RP-S/ RP-A). Gen b -actina (OB-S/ OB-A)

\begin{tabular}{llcc}
\hline Nombre & Partidor & $\mathbf{N}^{\circ}$ Acceso GenBank & Fuente \\
\hline RE-S & CTCCACGATCAAGTCCACCT & AY033393 & \\
RE-A & ACGGAACCGAGACGATGTAG & AY033393 & \\
RP-A & TGTGCTGGAAGAAACGATTG & Z66555.1 & \\
RP-S & TAGGGCTTGGCTTTCATTT & Z66555.1 & \\
OB-S & AACTCCATCATGAAGTGTGAC & & Dzidic et al. \\
OB-A & GATCCACATCTGCTGGAAGG & & Dzidic et al. \\
\hline
\end{tabular}
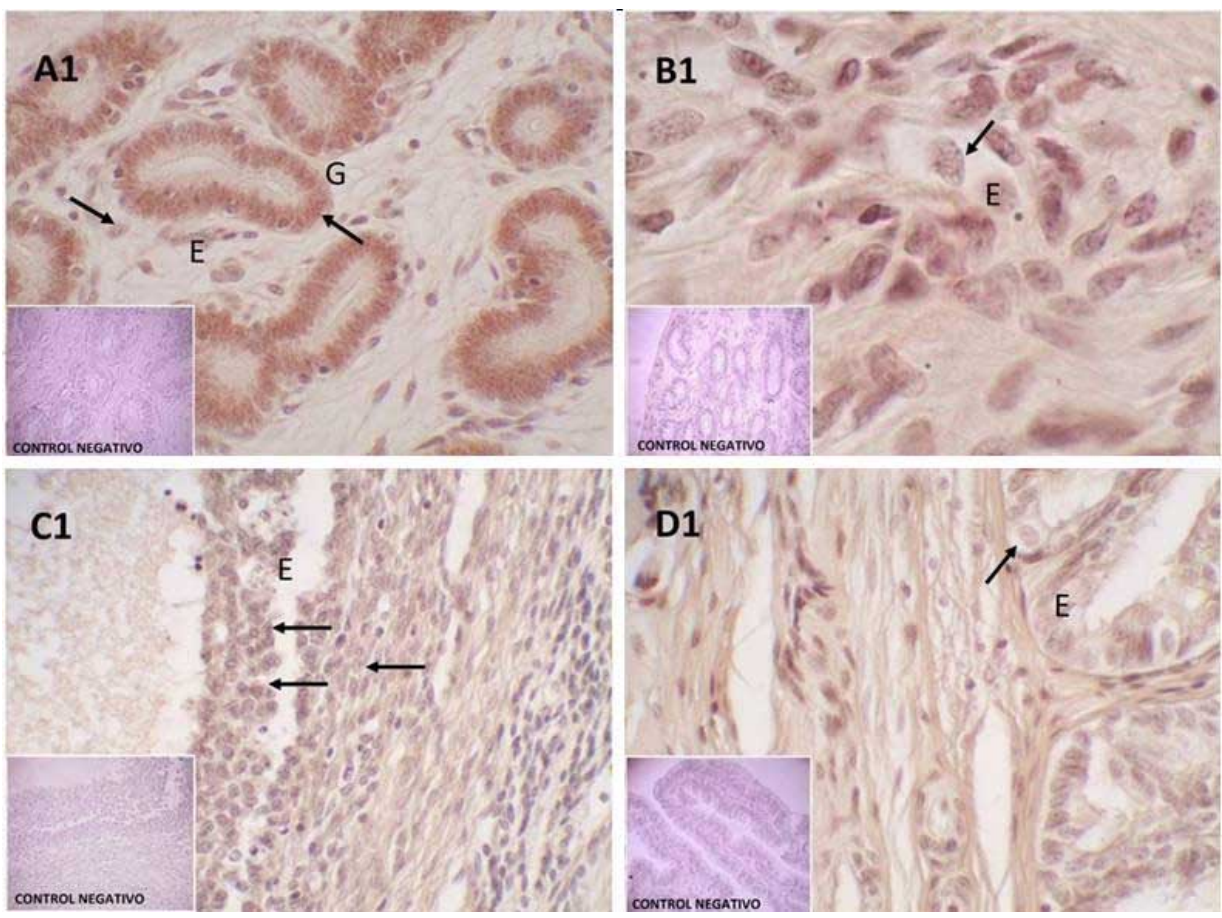

Fig. 1. Análisis inmunohistoquímico del receptor de estrógeno en órganos del sistema reproductivo de ovejas de raza Texel. A1. Cuerno, B1. Cervix, C1. Ovario, D1. Oviducto. 
presencia de los receptores de estrógenos en zonas carunculares y glandulares, siendo mas intensa en células del epitelio glandular y en células estromales (Fig.1). En ovario se destaca una señal de menor intensidad en células de la granulosa y células estromales. En oviducto y cervix la señal en el epitelio es débil indicando baja expresión de este receptor (Fig. 1). En cuanto al receptor de progesterona la distribución de la expresión es similar al receptor de es- trógeno, pero con mucho menor intensidad (Fig. 2).

A nivel de la cantidad de transcritos detectados mediante PCR en tiempo real, se destaca un mayor nivel de expresión tanto del receptor de estrógeno como de progesterona en el endometrio (Figs. 3 y 4). Los transcritos de ambos receptores también se detectaron en cervix y oviducto pero en mucho menos cantidad (Figs. 3 y 4 ).
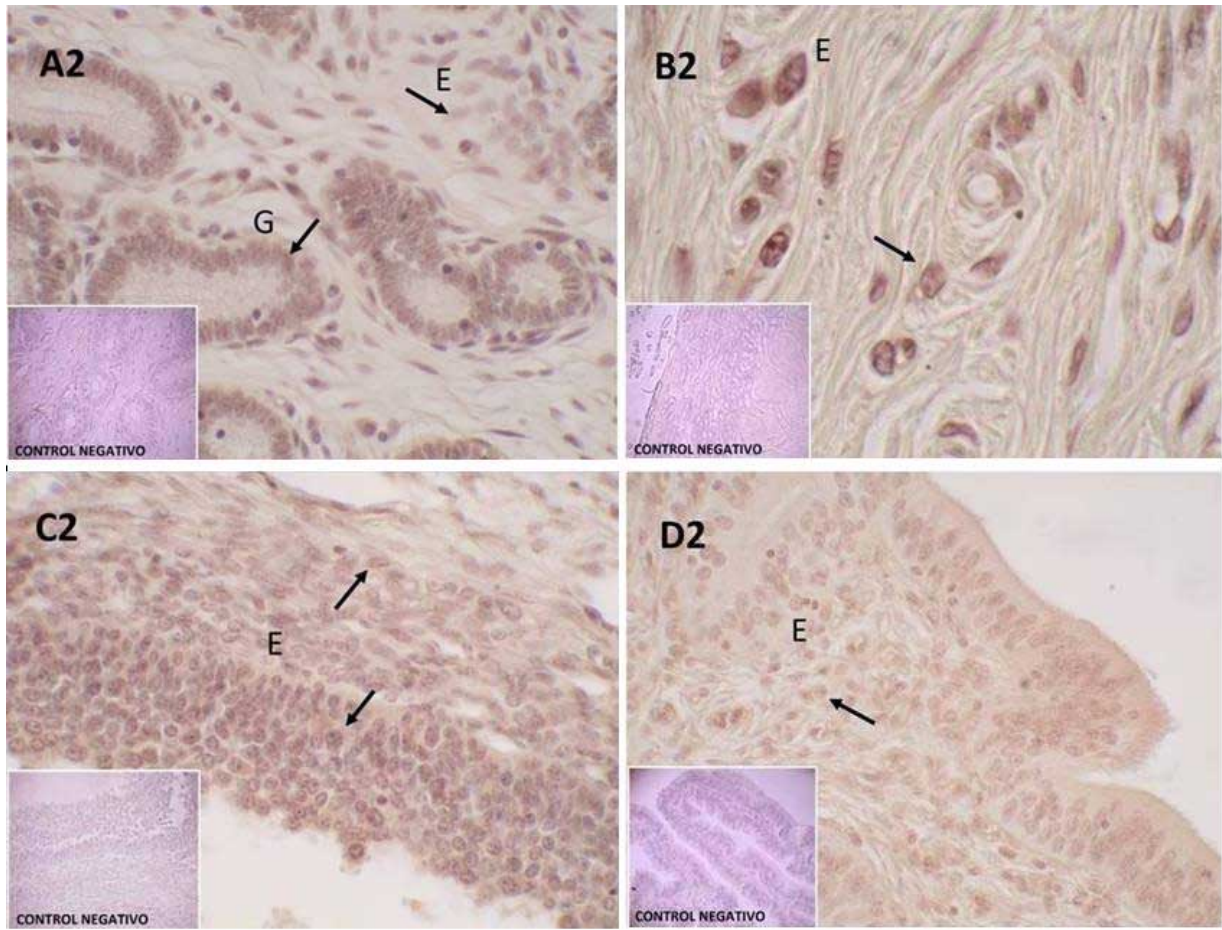

Fig. 2. Análisis inmunohistoquímico del receptor de progesterona en órganos del sistema reproductivo de ovejas de raza Texel. A1. Cuerno, B1. Cervix, C1. Ovario, D1. Oviducto.

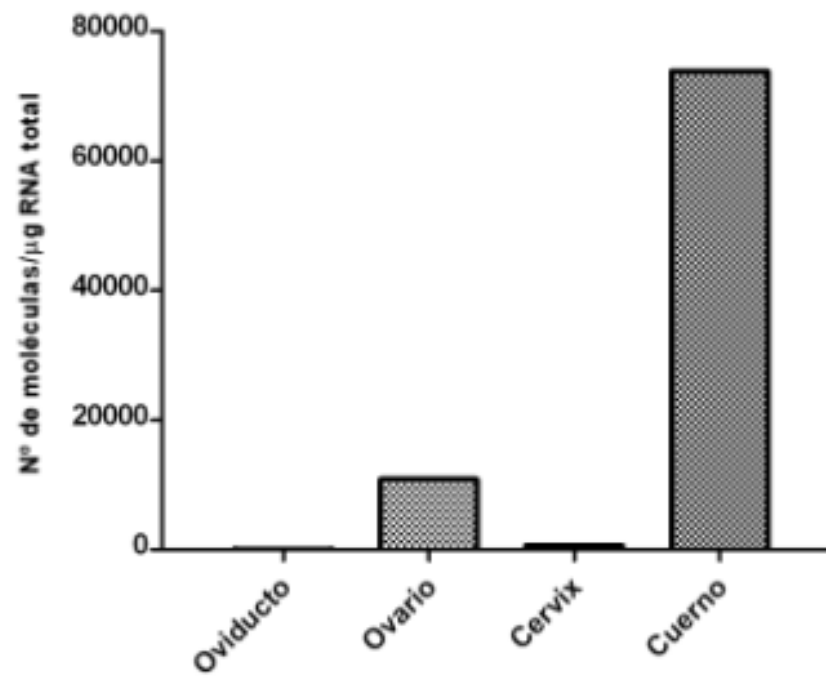

Fig. 3. Nivel de expresión del transcrito del receptor de estrógeno en sistema reproductor de ovejas Texel. Los datos por órgano, representan el promedio de tres medidas independientes.

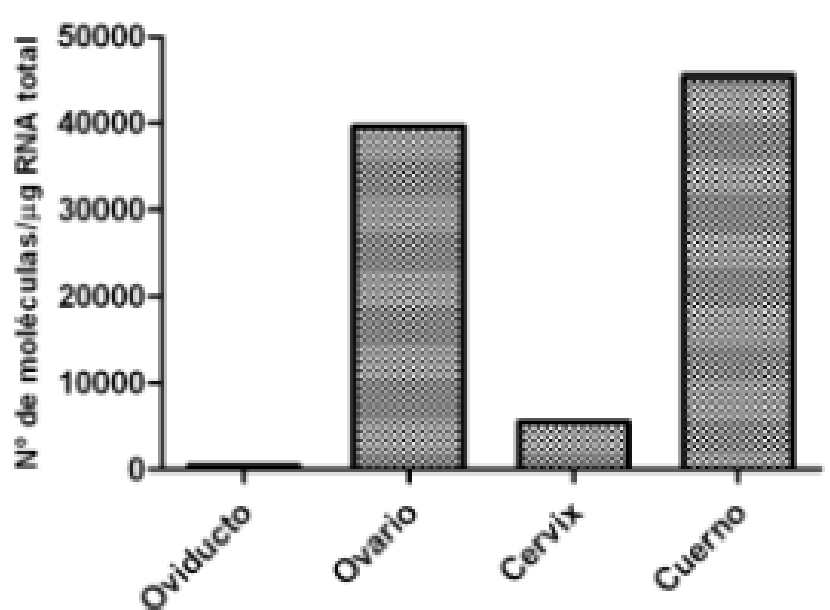

Fig. 4. Nivel de expresión del transcrito del receptor de progesterona en sistema reproductor de ovejas Texel. Los datos por órgano, representan el promedio de tres medidas independientes. 


\section{DISCUSIÓN}

El comportamiento reproductivo de los ovinos varía entre las diferentes razas. Dentro de los factores que inciden en la capacidad reproductiva, se encuentra la expresión y distribución de receptores de estrógenos (RE) y progesterona (RP) en su tracto genital. La expresión de RE y RP en animales prepúberes y adultos se ha detectado en ovejas de la raza Corriedale (Garofolo \& Tasende, 1996) y Romney Marsh (Meikle et al., 1997; Meikle et al., 2004; Vasconcellos et al., 2005). Ya es conocido que la respuesta reproductiva a nivel celular depende de múltiples factores, entre ellos el número y afinidad de los receptores hormonales en los tejidos del sistema reproductor, el estadio reproductivo en el que se encuentre la hembra, factores ambientales, entre otros (Meikle et al., 2004). Si bien se ha estudiado la presencia de RE y RP en diferentes especies animales demostrando diferencias entre ellas (Meikle et al., 2004), y en hembras ovinas prepúberes (Vasconcellos et al., 2005), no existen estudios anteriores en hembras ovinas adultas de razas Texel. Relacionado con lo anterior, la evidencia indica que ovinos de raza Texel poseen altos índices de prolificidad, (Riquelme, 2005 ). Estudios previos nuestros, en ovejas de raza Araucana y Romney Marsh referentes a la presencia de estos receptores en tracto genital mostraron que la expresión de RE y RP es siempre detectable, variando la intensidad de su expresión según su etapa de desarrollo y estadio reproductivo, no mostrando diferencias significativas entre ambas razas (Vasconcellos et al., 2005), destacándose elevados niveles de expresión endometrio respecto a otros tejidos del sistema reproductivo (Vasconcellos et al., 2009a, 2010). Este estudio también indica mayor expresión tanto de la proteína como del RNA en endometrio, lo cual se relaciona con el papel de estos receptores a nivel de desarrollo morfofuncional de este tejido durante el desarrollo del animal.
Se sabe que durante la fase estrogénica del ciclo sexual, la influencia de los estrógenos aumenta la cantidad de sus receptores en el tracto reproductivo, y además estimula la síntesis de receptores para progesterona y andrógenos para continuar con la segunda etapa del ciclo sexual (Bellido \& Bellido, 1999; Meikle et al., 1996). Esto explicaría la presencia de ARNm de RP en tejidos de ovinos adultos, que aunque presente, producirá la expresión de proteína detectable en grandes cantidades sólo al llegar a la fase luteínica del ciclo. Esto concuerda con los hallazgos de Spencer \& Bazer donde detectaron el RP por análisis inmunohistoquímico y además su RNAm, y se demostró que la expresión de RP disminuía durante el ciclo estral, mientras que su RNAm está presente durante esta etapa, pero disminuyendo en cantidad a lo largo de los días, hasta llegar a la segunda fase del ciclo, determinado por la hormona progesterona, donde aumenta al igual que los receptores.

Este trabajo demuestra que tanto el receptor de estrógeno como de progesterona están expresados en sistema reproductivo de ovejas de raza Texel en una distribución similar a lo encontrado en otras razas de ovejas quedando por definir si los niveles de expresión son similares entre razas.

\section{CONCLUSIÓN}

La distribución de la expresión de los receptores de estrógeno y progesterona en raza Texel es similar a lo encontrado en otras razas de ovejas. Sin embargo este estudia no permite deducir diferencias en los niveles de expresión lo cual se proyecta hacer en un siguiente trabajo.

VASCONCELlOS, C. M.; PAREDES, H. M.; HERNÁNDEZ, V. C.; MUÑOZ, S. A. \& NAVARRETE, J. Expression of estrogen and progesterone receptors in the genital tract of Texel ewes. Int. J. Morphol., 29(4):1268-1273, 2011.

SUMMARY: Reproductive performance of sheep varies between different races. Among the factors that affect the reproductive capacity, the level of expression of estrogen and progesterone receptors in the genital tract appears to have a relevant role. In the endometrium, oviduct and ovarian estrogen and progesterone regulate the expression of numerous proteins involved in morphofunctional development. Genetic factors such as race would be related to expression levels of these receptors. The Texel ewes have high fertility rates, are very prolific and have a high percentage of multiple births which could be related to the expression of these receptors in the reproductive tract. The aim of this study was to evaluate the expression of estrogen and progesterone receptors in the genital tract of ewes and Texel high prolificacy. The expression of the receptor protein of both receptors was detected by immunohistochemistry and the level of expression of the transcripts by Quantitative RT-PCR Real-Time. The results showed immunohistochemical expression of estrogen receptor mainly in areas of glandular and caruncular endometrium. It also highlights a lower expression of both receptors in ovarian tissue, epithelium of the oviduct and cervix. Expression of progesterone receptor immunohistochemical level is much lower with weaker signal in endometrium and ovaries. The expression level of transcripts remains the same distribution as immunohistochemical signals for both receptors. We conclude that both receptors are expressed in the reproductive system Texel ewes in a distribution similar to that found in other breeds of sheep, must be defined if the levels of expression are similar in different races.

KEY WORDS: Reproductive system; Estrogen receptors; Progesterone receptors; Texel race. 


\section{REFERENCIAS BIBLIOGRÁFICAS}

Bellido, B. \& Bellido, S. Receptores de estrógeno y progesterona. Ginecología y Obstetricia. 45(1), 1999. Disponible en: http:/ /sisbib.unmsm.edu.pe/bvrevistas/ginecologia/vol_45n1/ receptores_estrogenos.htm

Cherny, R. A. Inmunohistochemical localization of estrogen receptors in the endometrium of the ewe. Reprod. Fertil. Dev., 3:321-31. 1991.

Chomczynski, P. \& Sacchi, N. Single-step method of rna isolation by acid guanidinium thiocyanate-phenol-chloroform extraction. Anal. Biochem., 162(1):156-9, 1987.

Cunningham, J. Ciclos reproductivos en Fisiología Veterinaria. México D.F., Interamericana McGraw-Hill, 1998. pp.494502.

Dzidic, A.; Kaps, M. \& Bruckmaier, R. M. Machine milking of Istrian dairy crossbreed ewes: Udder morphology and milking characteristics. Small Rum. Res. 55(3):183-9. 2004.

Garofalo, E. G. \& Tasende, C. Uterine estrogen and progesterone receptors in prepuberal ewe: distribution in myometrium, endometrium, and caruncles. Vet. Res., 27(2):177-83, 1996.

Ing, N. H. \& Ott, T. L. Estradiol up-regulates estrogen receptoralpha messenger ribonucleic acid in sheep endometrium by increasing its stability. Biol. Reprod., 60(1):134-9, 1999.

Meikle, A.; Garófalo, E. G; Rodríguez-Piñón; M.; Tasende, C. \& Shalin, L. Regulation by gonadal steroids of estrogen and progesterona receptors along the reproductive tract in female lambs. Acta Vet. Scand., 42(1):161-9, 2001.

Meikle, A.; Tasende, C.; Rodríguez, M. \& Garófalo, E. G. Effects of estradiol and progesterone on the reproductive tract and on uterine sex steroid receptors in female lambs. Theriogenology, 48(7):1105-13, 1997.

Meikle, A.; Tasende, C.; Sosa, C. \& Garófalo, E. G. The rol of sex steroid receptors in sheep female reproductive physiology. Reprod. Fertil. Dev., 16(4):385-94, 2004.

Pfaffl, M. W. A new mathematical model for relative quantification in real-time RT-PCR. Nucleic Acids Res., 29(9):e45, 2001.

Priedkkalns, J. Sistema reproductor femenino. En: Dellmann, D. Histología Veterinaria. $2^{\text {a }}$ Ed. Zaragoza, Acribia S. A., 1993. pp.279-83.

Riquelme, J. Medición de características productivas de ovinos de raza Texel del sector de Pillanlelbún en la IX Región. Tesis de grado, Universidad Católica de Temuco, Temuco, Chile, 2005.
Spencer, T. E. \& Bazer, F. W. Temporal and spatial alterations in uterine estrogen receptor and progesterone receptor gene expression during the estrous cycle and early pregnancy in the ewe. Biol. Reprod., 53(6):1527-43, 1995.

Vasconcellos, A.; Sepúlveda, N.; Castillo, J. \& Rosas, C. Presencia de receptores de Estrógeno y de Progesterona en el Endometrio de ovejas Prepúberes. Estudio inmunocitoquímico. Int. J. Morphol., 23(4):393-6, 2005.

Vasconcellos, A.; Paredes M.; Carrasco, J. \& Núñez D. Analysis of the Expression of Estrogen and Progesterone Receptors in the Endometrium of Ewes of the Races Romney Marsh and Araucana. Int. J. Morphol., 27(1):97-100, 2009a.

Vasconcellos, A.; Paredes, M.; Núñez, D.; Barrientos, E.; Olmazabal, Y.; Navarrete, J. \& Molina, B. Analysis of the Expression of Estrogen Receptors in the Endometrium of Ewes Fed with Normal and Supplementary Diet. Int. J. Morphol., 27(4):1093-8, 2009b.

Vasconcellos, A.; Paredes, M.; Núñez, D.; Barrientos, E.; Olmazabal, Y.; Navarrete, J. \& Molina, B. Study of the Expression of Progesterone Receptors in the Endometrium of Ewes with Normal and Supplementary Diet. Int. J. Morphol., 28(2):575-81, 2010

Vasconcellos, C. A.; Sepúlveda B. N. \& Pacheco, C. C. Presencia de receptores de estrógeno, progesterona y de $\mathrm{CBG}$ en el tracto genital de ovejas y de perras. Estudio inmmunocitoquímico. Int. J. Morphol., 24(3):457-62, 2006.

Wiley, A. A.; Bartol, F. F. \& Barron, D. H. Histogenesis of the ovine uterus. J. Anim. Sci., 64(4):1262-9, 1987.

Dirección para correspondencia:

Adriana Vasconcellos C.

CEBIOR, Centro Biotecnológico de la Reproducción

Universidad de La Frontera, Temuco

CHILE

Email: avascon@ufro.cl

Recibido : 01-08-2011

Aceptado: 23-09-2011 